\title{
Effect of Micro Jet Control on the Flow Filed of the Duct at Mach 1.5
}

\author{
S A Khan, Abdul Aabid, Imran Mokashi, Zaheer Ahmed
}

\begin{abstract}
This article reports the outcome of the windtunnel investigation on the role of micro jets as an active control on the wall pressure distribution. Four tiny jets of $1 \mathrm{~mm}$ diameter located at 90-degree intervals along a pcd of 1.3 are employed for the control. The Mach number considered for suddenly expanded flow through the nozzle is 1.5, and the microjets are expanded suddenly into a duct at the base with an area ratio of 3.24 times the $C D$ nozzle exit area. The $L / D$ ratio of the duct was reduced from 10 to 1 in steps of 1 . The nozzle pressure ratio (NPR) was operated at 3 to 11 with and without control. The wall pressure distribution is observed in the suddenly expanded axi-symmetric duct. From the results, it has been found that the wall pressure distribution does not adversely influence the micro jet controller.

Keywords-Wall pressure, L/D ratio, NPR, Mach Number.
\end{abstract}

\section{INTRODUCTION}

The study of base drag during a sudden expansion of fluid is of vital importance in the area of aerodynamics. In projectiles, missiles, rockets and the rear body of the fighter planes, base drag due to flow separation at the base of the aerodynamic body contributes to a more significant portion of the total drag. For instance, a base drag contribution can be as high as seventy percent of the total drag for a rocket with power off. Massive-scale flow unsteadiness, frequently related to the turbulent separated flow, can introduce additional difficulties like base buffeting, which are unwanted.

Due to broad applications of suddenly expanded flows in aerodynamic and re-entry vehicles, the present investigation is motivated to analyze the behavior of base flow from a converging-diverging nozzle. A number of methods and research works are available which talk about the regulation and reduction of base drag by controlling the base pressure using active and passive controls. The following section provides a detailed review of literature works reported on the use of novel techniques to control the base drag.

\section{LITERATURE SURVEY}

Khan et al. [1]-[3], experimentally investigated the effectiveness of micro jet in controlling base pressure in an axisymmetric tube. Tinyjets four in the number of $1 \mathrm{~mm}$ orifice diameter located at 90-degree interval at pcd of 1.3 were positioned in the base region as a control mechanism for the enlarged duct flow field. The Mach numbers

Revised Manuscript Received on August 19, 2019.

S A Khan,Mechanical Engineering Dept. Faculty of Engineering, IIUM Kuala Lumpur, Malaysia. (sakhan@iium.edu.my)

Abdul Aabid,Mechanical Engineering Dept. Faculty of Engineering, IIUM Kuala Lumpur, Malaysia.

Imran Mokashi,Mechanical Engineering Dept. Faculty of Engineering, IIUM. Kuala Lumpur, Malaysia.

Zaheer Ahmed, Mechanical Engineering Dept. Faculty of Engineering, IIUM, Kuala Lumpur, Malaysia. considered by the authors for the suddenly expanded flow were $1.25,1.30,1.48,1.6,1.8$, and 2.0 with an axissymmetric duct of area ratio $2.56,3.24,4.84$, and 6.25 times that of CD nozzle exit diameter of $10 \mathrm{~mm}$. The duct L/D ratio of the suddenly expanded flow regime was varied from reversely 10 to 1 . In their other work [4], [6], they investigated the effectiveness of microjet control under the influence of over, under, and correct expansion to control the base pressure at the nozzle exit. Four micro-jet of onemillimeter orifice diameter located at ninety-degree intervals along a PCD of 1.3 times the nozzle exit diameter in the base region was placed as active controls. Experimental examinations were carried for Mach numbers 1.5, 1.3, 1.6, $1.8,2.0,2.5$, and 3.0. The micro-jet used for an area ratio of 2.56 .

Baig et al. [7] presented an investigation on base pressure control in suddenly expanded flow with the microjet as the control mechanism. Experiments were conducted to assess the usefulness of active control. Micro jets at four locations of the base region, symmetric to the CD nozzle axis were used as the active control. The jet Mach numbers at the exit of the flow accelerating devices were 1.87, 2.2, and 2.58. The area ratio of the duct for experiments selected was 2.56 . The L/D ratio of the sudden expanded circular pipe considered was from 10 to 1 . The flow accelerating devices (i.e., the Nozzles) generating the above Mach numbers and the carrying the inertia levels were operated, and tests were conducted with nozzle pressure ratio (NPR) in the range 3 , $5,7,9$, and 11 . Baig et al. [8] in their work, experimentally investigated airflow through the $\mathrm{CD}$ axi-symmetric nozzles into a circular tube of more significant area ratio focusing on the base pressure and flow established in the sudden expansion duct.

Vikramaditya et al. [9] investigated the pressure-flow variations experimentally in the base region of a characteristic missile shape at a freestream subsonic flow of Mach number 0.7. Their purpose was to characterize the pressure-flow variations and explained the effect of base cavities on its performance. They conducted experiments for unsteady pressure measurements at six azimuthal positions. Considerable fluctuations in the characteristics of pressureflow were observed in the azimuthal direction laterally due to the irregularity of the model. The base cavities were realized to improve the base pressure and decrease the root mean square of the pressure variations. They showed that the higher-order moments provide lessening tendency as the length of the base cavity is augmented.

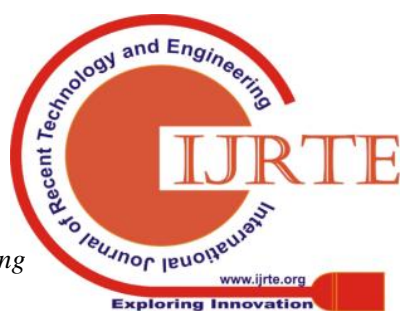


Chaudhary et al. [10], [11] studied the consequence of the tests pertinent to the flow control at the base in the recirculation zone. Micro jets of one-millimeter orifice diameter placed at ninety-degree separation at a PCD of 1.3 times at the periphery of the CD nozzle having exit diameter of $10 \mathrm{~mm}$ in the base region were employed as the dynamic control mechanism. In this work, base pressure for Mach values 1.1 to 1.3 are measured with the control and the wall pressure variation is provided for Mach 1.6 and Mach 1.8. Axi-symmetric circular brass pipes were used for the expansion of flow for jets exiting from the nozzles, and the cross-sectional area ratio of ducts was 2.56. L/D ratio of the broadened pipe was varied from 10 to 1 , and the NPR testedwerefrom 3 to 11 .

The study was carried out to assess the usefulness of the flow regulations in the form of tiny jets to control the pressure in the base region of an abruptly expanded duct [12]. Experimentally investigated the microjets control duct for an area ratio of 7.56 [13], 2.56 [14], 3.24 [15], [16], 4.84 [17]. Also, the results were numerically simulated and validated with the experimental results [10] and also, simulated the base pressure reattachment lengths for different flow condition (i.e., Mach number, area ratio, and the level of expansion) [18].

On the other hand, the CFD method as a tool of numerical simulation has also been used to investigate the flow-field in CD nozzle. A two-dimensional planar CD Nozzle was modeled and analyzed in ANSYS commercial code [19]. For the analysis of the results, a k- $\varepsilon$ turbulence model with standard wall function effect has been used with the ideal gas equation. From the contours and plots, pressure, and velocity flow from the inlet to the outlet of the planar nozzle were observed [20]-[24]. The CFD method was also used for a wedge model to investigate the shock wave formation at supersonic flow regimes [25], [26]. Investigated the flowfield for non-circular cylinder using CFD method [27]. Moreover, in some studies, it is found that the CD nozzle designed and modeled using CFD code along with densitybased effect [28]-[31]. Nevertheless, to the best of the author's information, there is no work stated with active control effect of wall pressure distribution for Mach number 1.5 and area ratio of 3.24. Consequently, in the current work, an effort is made to investigate the wall pressure distribution with active control in the form of a microjet controller under an auspicious pressure gradient and compared the flow field with an internal and the external flows using CFD method [32]. They concluded from their studies that the nature of the flow seems to be identical without introducing any complications in the flow field. They further stated that the internal flow has several distinct advantages. Base pressure control in $\mathrm{CD}$ nozzle using a small cylinder also been found, and they controlled base pressure two methods such as active and passive control [33] - [37].

\section{EXPERIMENTAL INVESTIGATION}

Fig. 1 shows the details of sudden expansion flow filed showing the dividing streamlines, reattachment length as well as the point, expansion waves, and recirculation zone and the development of the boundary layer. The same concept is used to perform the experimental investigation with the application of four micro jets at the base, as shown in Fig. 1. Fig. 2 demonstrates the setup used for the experiment in the present study, which is also discussed in [1]. The investigation was performed using experimental setup made up of the circular pipeline network of cost iron, settling chamber made up of forged mild steel, and pressure transducers from the national instruments which can withstand extream weather conditions. The pressure transducer can be used at a temperature as high as $50^{\circ} \mathrm{C}$ at a high level of humidity without sacrificing the accuracy and repeatability of the results.

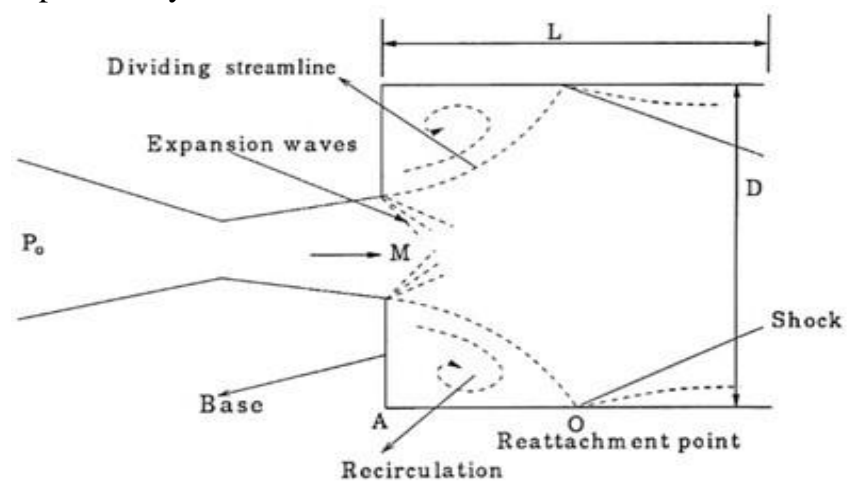

Fig. 1. The Flow Field with Sudden Expansion.

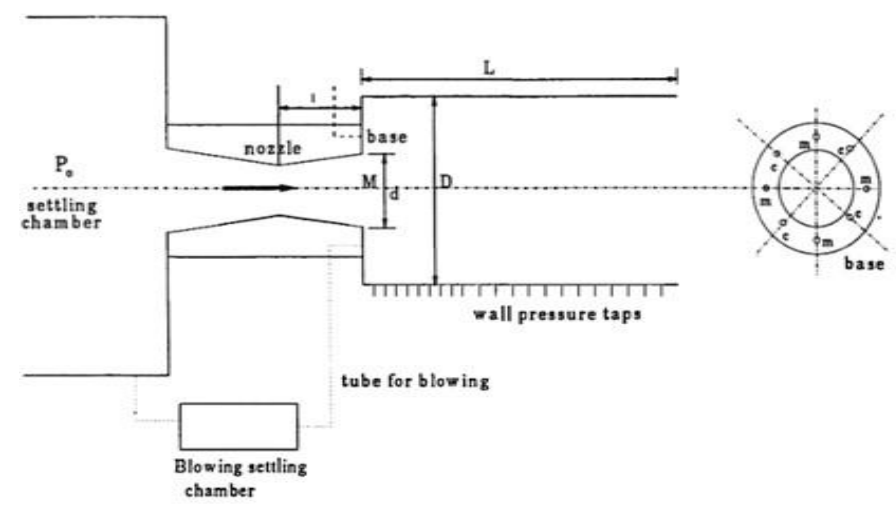

Fig. 2. The Wind-tunnel Test Setup.

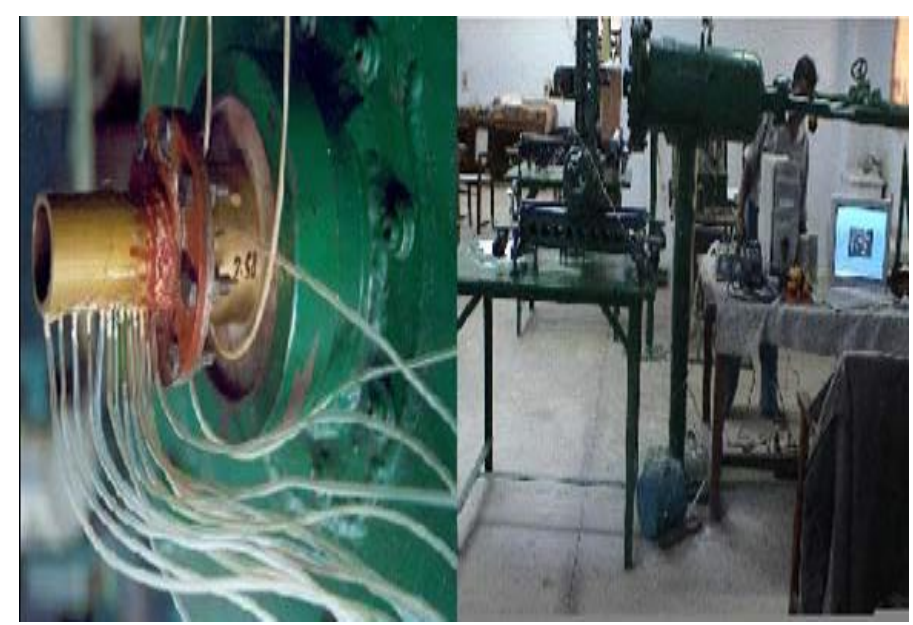

Fig. 3. A View of the circular Duct with Pressure Tapings Blue Eyes Intelligence Engineering \& Sciences Publication 
The gas is allowed to pass through the predetermined values and regulated then and adequately through the model of experimentation. Duct attached to the nozzle is the experimental model for the flow development, and the measurement of the base pressure and the wall pressure are planned and to achieve the objective the tiny jets are employed here. The flow expanding from the nozzle and reaching the end downstream of the duct is exposed to ambient atmospheric pressure. In Fig. 2, the schematic view of the setup used for the analysis is shown. Fig. 3 show the remaining arrangement involved in the setup. At the nozzle exit and base of the duct $1 \mathrm{~mm}$ holes, eight in number are arranged to blow jet using 4 holes at the base corner of the flow. The remaining four holes are for the pressure measurement at the base. Along the length of the duct, the wall pressure taps are provided to measure and record the wall pressure along with the flow in the duct. The pressure range is a $0-15$ bar of the transducer employed, and it has 16 channels. The sampling rate of the pressure transducer is 250 samples per second, and then the reading is displayed on the monitor and recorded. The wall pressure was recorded using mercury multi-tube manometer as the pressure transducer has only sixteen channels. The pressure transducer was used in the area where the flow is susceptible; there are many activities that are taking place due to the expansion, compression, and recombination of the flow in the enlarged duct. The flow after exiting from the duct gets reattached with the duct wall, and pressure recovery also takes place. The process of recombination, reflection from the wall will continue until the flow has attained the ambient conditions.

\section{RESULTS AND DISCUSSION}

Fig. 4 present the wall pressure distribution in the enlarged duct for area ratio 3.24, for some selected combination of Inertia levels. For this area ratio of 3.24, the area of the duct marginally more substantial than the area ratio of 2.56 where the duct diameter is $16 \mathrm{~mm}$ and in this case it $18 \mathrm{~mm}$ and it is the case of slightly increased relief for the expanding flow.

Wall pressure results for Mach 1.5 are shown in Figs. 4. It is seen from these results that, for $L / D=10$ and $M=1.5$ the control influence is minimal (as in the case of Figs. 4(a) and it does not influence the wall pressure adversely. There is a marginal change in the wall pressure values for the higher NPR. Further, it is seen that for NPR 3 and 5, the fluctuations in the wall pressure are at the minimum level. Moreover, these are limited within $10 \%$ distance from the exit of the duct diameter, whereas for all the NPR's the static wall pressure flow field by itself is oscillatory due the flow being over, under, and ideally expanded. Hence, due to the small increase in the relief available to the flow, the flow will not be oscillatory in nature as the shear layer exiting from the nozzle gets the increased area to expand, and the control effectiveness is nominal.

Fig. 4 (b) presents similar results of the wall pressure data for $L / D=8$, as was observed in the previous figure. Figs. $4((c)$ to $(d))$ represent the wall pressure outcome for $L / D=6$ and 5 with the exception that due reduction in the L/D ratio there is some influence of backpressure and the peak pressure values are higher than that those were for higher
$\mathrm{L} / \mathrm{D}$ ratios namely at $\mathrm{L} / \mathrm{D}=5(\mathrm{~L} / \mathrm{D}=10$ and 8$)$ respectively. The results in the figure indicate that the flow field once again has smoothened in the duct and the wall pressure values with and without control are identical and not getting aggravated due to the presence of the control mechanism. This trend continues until $\mathrm{L} / \mathrm{D}=4,3$, and 2 (Figs. 4((e) to (g)), then later for lowest $\mathrm{L} / \mathrm{D}$ like $\mathrm{L} / \mathrm{D}=1$, the flow in the duct remains attached to the walls because of which the length is found to be insufficient.
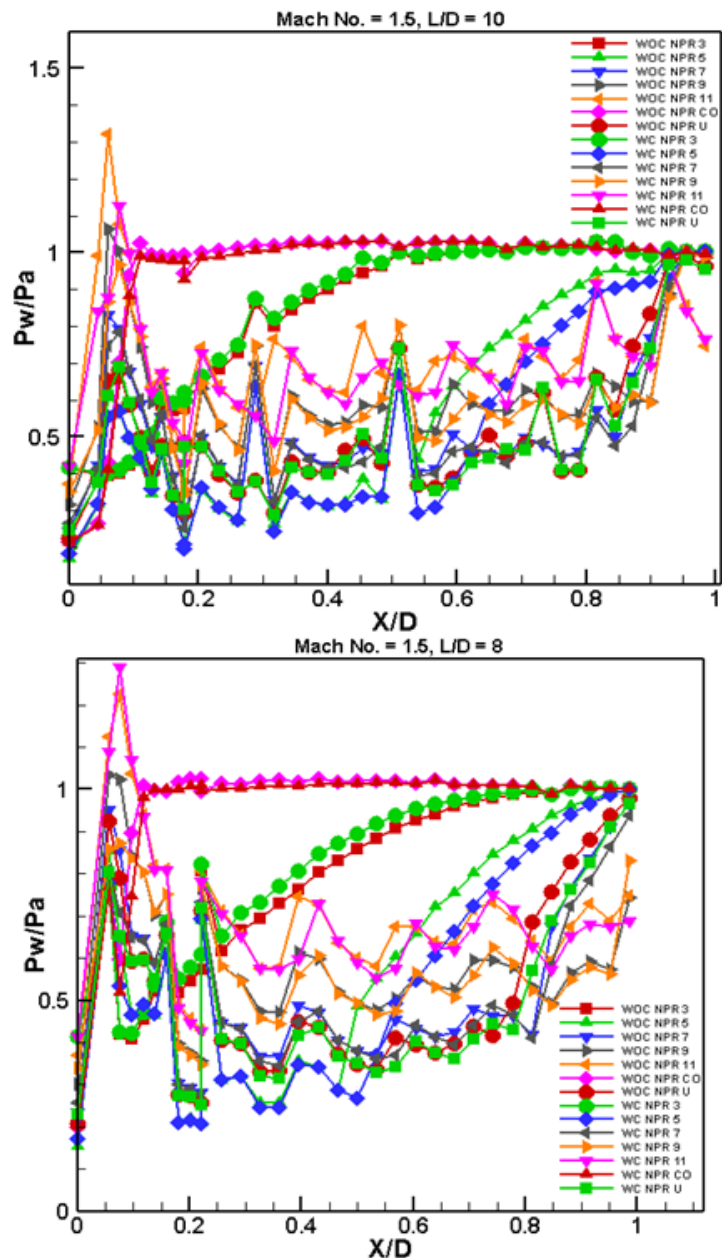

(b)

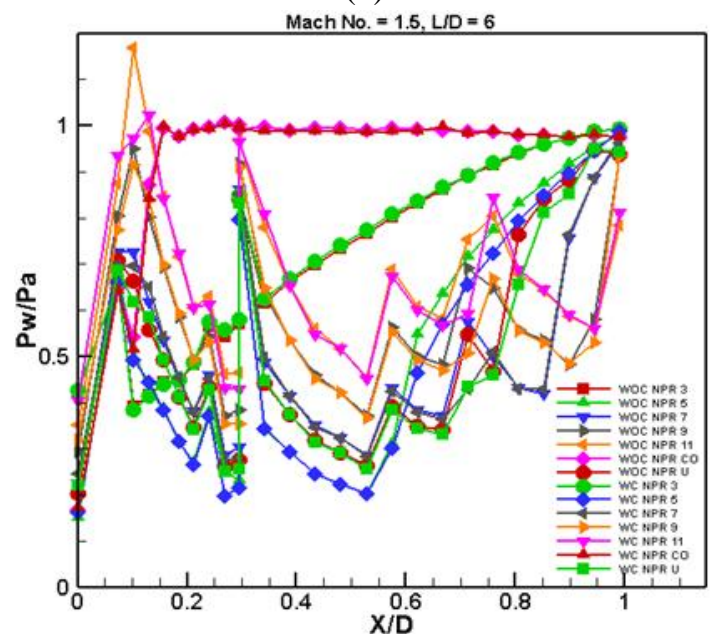

(c) 


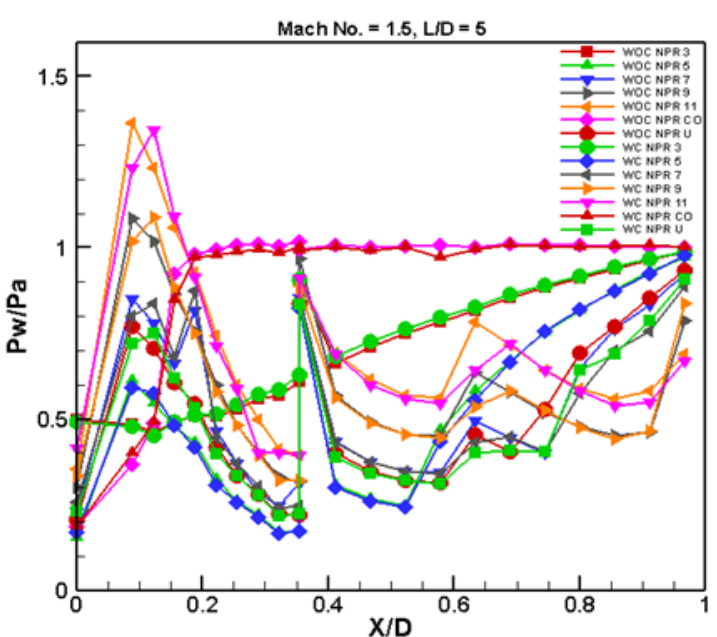

(d)

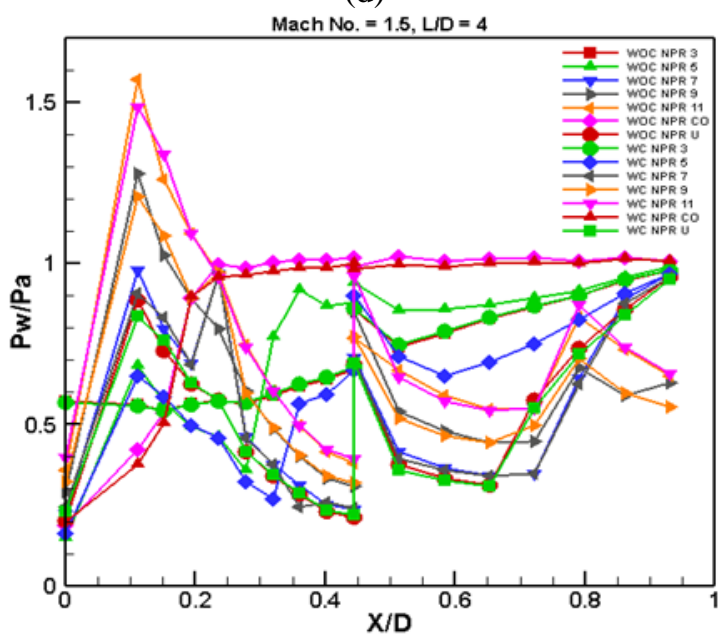

(e)

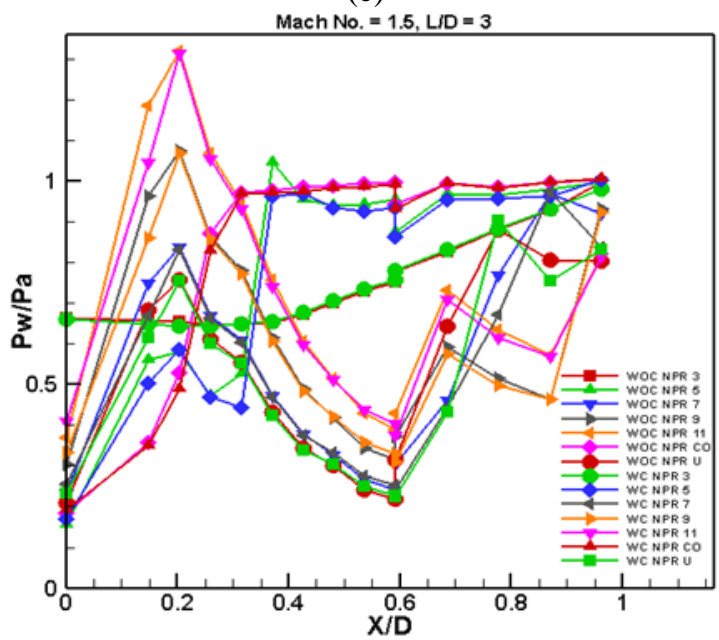

(f)

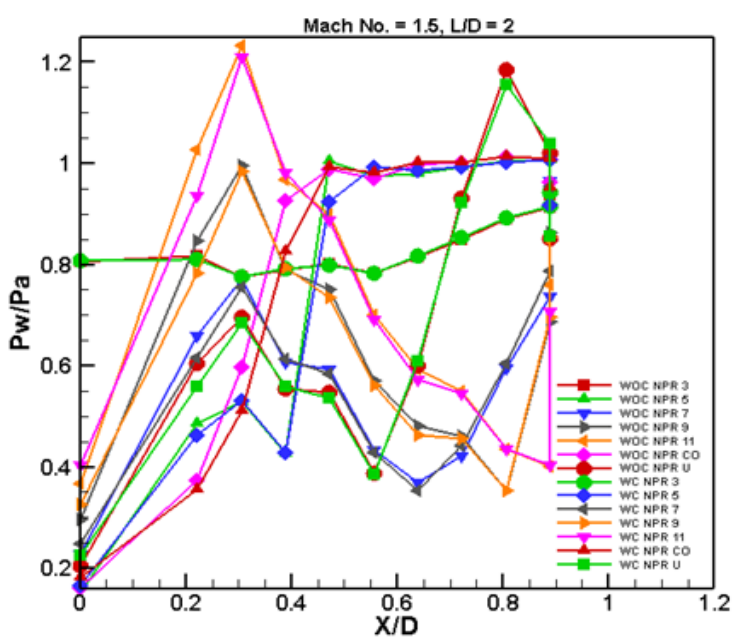

(g)

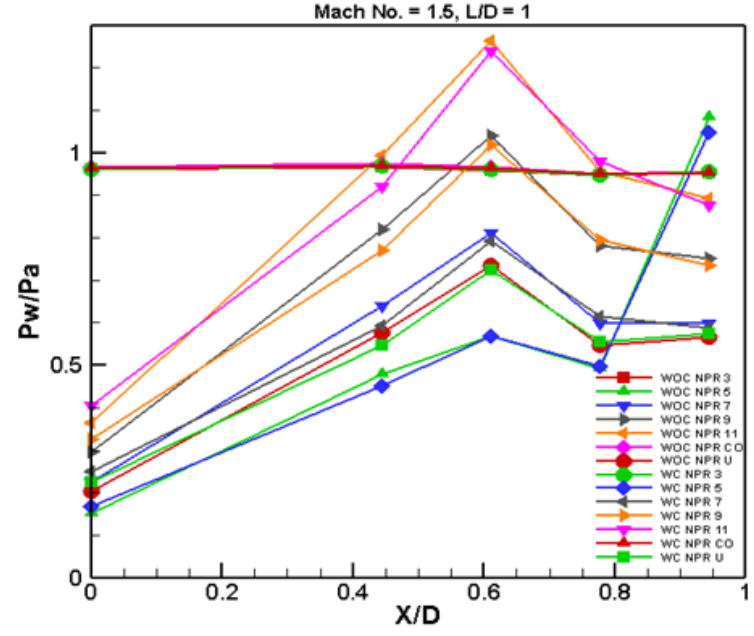

(h)

Fig. 4. Wall Pressure Vs. X/D

\section{CONCLUSION}

Wall pressure distribution in suddenly expanded flow into a duct of area ratio 3.24 with and without control is investigated in detail in the present work. The Mach number selected for the present analysis is fixed at 1.5. The L/D ratio of the suddenly expanded circular pipe where the flow expands is varied from 10 to 1 . From the investigation on wall pressure distribution, the following conclusions are drawn:

- At 3.24 area ratio, the Mach 1.5 the analysis for base pressure show a significant increase in the base pressure, and hence the effectiveness of the control is visible.

- The use of micro jets resulted in a decrease of the suction at the base and hence decrease in the associated base drag for the parameters adopted here. This has caused improvement in the pressure at recirculation zone at the corner.

- The prime outcome of this experimental investigation is that active control does not adversely affect the static duct pressure in the suddenly expanded duct and hence the resulting flow field of the circular duct.

Published By:

Blue Eyes Intelligence Engineering

\& Sciences Publication

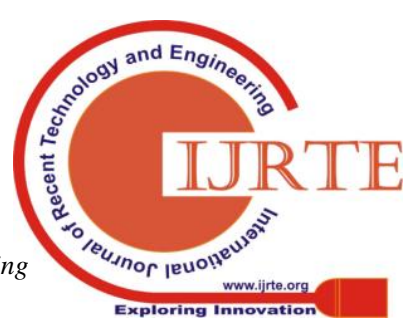




\section{REFERENCES}

1. S. A. Khan and E. Rathakrishnan, "Active Control of Suddenly Expanded Flows from Overexpanded Nozzles," International Journal of Turbo and Jet Engines, vol. 19, pp. 119-126, 2002.

2. S. A. Khan and E. Rathakrishnan, "Active Control of Suddenly Expanded Flows from Underexpanded Nozzles," International Journal of Turbo and Jet Engines, vol. 21, pp. 233-254, 2004.

3. S. A. Khan and E. Rathakrishnan, "Active Control of Suddenly Expanded Flows from Underexpanded Nozzles - Part II," International Journal of Turbo and Jet Engines, vol. 22, pp. 163-183, 2005.

4. S. A. Khan and E. Rathakrishnan, "Control of suddenly expanded flow," Aircraft Engineering and Aerospace Technology: An International Journal, vol. 78, no. 4, pp. 293-309, 2006.

5. S. A. Khan and E. Rathakrishnan, "Nozzle expansion level effect on suddenly expanded flow," Int. J. Turbo Jet Engines, vol. 23, no. 4, pp. 233-258, 2006.

6. S. Rehman and S. A. Khan, "Control of base pressure with micro-jets : part I," Aircr. Eng. Aerosp. Technol., vol. 80, no. 2, pp. 158-164, 2008.

7. M. A. A. Baig, F. Al-Mufadi, S. A. Khan, and E. Rathakrishnan, "Control of Base Flows with Micro Jets Control of Base Flows with Micro Jets," International Journal of Turbo and Jet Engines, vol. 28, no. April 2015, pp. 59-69, 2011.

8. M. A. A. Baig, S. A. Khan, and E. Rathakrishnan, "Active control of base pressure in suddenly expanded flow for area ratio 4.84 ," Int. J. Eng. Sci. Technol., vol. 4, no. 05, pp. 1892-1902, 2012.

9. N. S. Vikramaditya, M. Viji, and S. B. Verma, "Base Pressure Fluctuations on Typical Missile Configuration in the presence of Base Cavity," Journal of Spacecraft and Rockets, pp. 1-11, 2017.

10. Z. I. Chaudhary, V. B. Shinde, and S. A. Khan, "Investigation of base flow for an axisymmetric suddenly expanded nozzle with micro JET,' International Journal of Engineering \& Technology, vol. 7, pp. 236242, 2018.

11. Z. I. Chaudhary, V. B. Shinde, M. Bashir, and S. A. Khan, "Experimental Studies of the Base Flow From the Nozzles with Sudden Expansion with Microjets," Int. J. Energy, Environ. Econ., vol. 24, no. 1, pp. 59-66, 2016.

12. F. Ahmed and S. A. Khan, "Investigation of the efficacy of low length-to-diameter ratio and nozzle pressure ratio on base pressure in an abruptly expanded flow," in MATEC Web of Conferences, 2018 , vol. 01004, pp. 1-6.

13. F. A. G. M, and S. A. Khan, "Active Control of Base Pressure using Micro Jets for Area Ratio of 7.56," Int. J. Innov. Technol. Explor. Eng., vol. 8, no. May, pp. 491-495, 2019.

14. S. A. Khan, A. Aabid, and Z. I. Chaudhary, "Influence of Control Mechanism on the Flowfield of Duct at Mach 1.2 for Area Ratio 2.56,” Int. J. Innov. Technol. Explor. Eng., vol. 8, no. 6S4, pp. 11351138, 2019.

15. M. H. Azami, M. Faheem, A. Aabid, I. Mokashi, and S. A. Khan, "Inspection of Supersonic Flows in a CD Nozzle using Experimental Method,” Int. J. Recent Technol. Eng., vol. 8, no. 2S3, pp. 996-999, 2019.

16. M. H. Azami, M. Faheem, A. Aabid, I. Mokashi, and S. A. Khan, "Experimental Research of Wall Pressure Distribution and Effect of Micro Jet at Mach,” Int. J. Recent Technol. Eng., vol. 8, no. 2S3, pp. 1000-1003, 2019.

17. S. A. Khan, I. Mokashi, A. Aabid, and M. Faheem, "Experimental Research on Wall Pressure Distribution in C-D Nozzle at Mach number 1.1 for Area Ratio 3.24," Int. J. Recent Technol. Eng., vol. 8, no. 2S3, pp. 971-975, 2019.

18. K. A. Pathan, P. S. Dabeer, and S. A. Khan, "Effect of nozzle pressure ratio and control jets location to control base pressure in suddenly expanded flows," J. Appl. Fluid Mech., vol. 12, no. 4, pp. 1127-1135, 2019.

19. K. A. Pathan, P. S. Dabeer, and S. A. Khan, "Influence of Expansion Level on Base Pressure and Reattachment Length," CFD Lett., vol. 11, no. 5, pp. 22-36, 2019.

20. ANSYS Inc, “ANSYS FLUENT 18.0: Theory Guidance," Canonsburg PA, 2017.

21. S. A. Khan, A. Aabid, and M. A. A. Baig, "CFD Analysis of CD Nozzle and Effect of Nozzle Pressure Ratio on Pressure and Velocity For Suddenly Expanded Flows," International Journal of Mechanical and Production Engineering Research and Development, vol. 8, no. June, pp. 1147-1158, 2018
22. A. G. M. Fharukh, A. A. Alrobaian, A. Aabid, and S. A. Khan, "Numerical Analysis of Convergent-Divergent Nozzle Using Finite Element Method," International Journal of Mechanical and Production Engineering Research and Development, vol. 8, no. 6, pp. 373-382, 2018.

23. A. Khan, A. Aabid, and S. A. Khan, "CFD analysis of convergentdivergent nozzle flow and base pressure control using micro-JETS," International Journal of Engineering and Technology, vol. 7, no. 3.29, pp. 232-235, 2018.

24. A. Aabid, A. Khan, N. M. Mazlan, M. A. Ismail, M. N. Akhtar, and S. A. Khan, "Numerical Simulation of Suddenly Expanded Flow at Mach 2.2," International Journal of Engineering and Advanced Technology, vol. 8, no. 3, pp. 457-462, 2019

25. S. A. Khan, A. Aabid, and C. A. Saleel, "Influence of Micro Jets on the Flow Development in the Enlarged Duct at Supersonic Mach number," International Journal of Mechanical and Mechatronics Engineering, vol. 19, no. 01, pp. 70-82, 2019.

26. S. A. Khan, A. Aabid, F. A. G. M, A. A. Al-Robaian, and A. S Alsagri, "Analysis of Area Ratio in a CD Nozzle with Suddenly Expanded Duct using CFD Method," CFD Lett., vol. 11, no. 5, pp. 61-71, 2019.

27. S. A. Khan, A. Aabid, and C. A. Saleel, "CFD Simulation with Analytical and Theoretical Validation of Different Flow Parameters for the Wedge at Supersonic Mach Number," International Journal of Mechanical and Mechatronics Engineering, no. 01, 2019.

28. S. A. Khan, A. Aabid, I. Mokashi, A. A. Al-Robaian, and A. S. Alsagri, "Optimization of Two-dimensional Wedge Flow Field at Supersonic Mach,” CFD Lett., vol. 11, no. 5, pp. 80-97, 2019.

29. M. F. M. Sajali, A. Aabid, S. A. Khan, F. A. G. M, and E. Sulaeman, "Numerical Investigation of Flow Field of a Non-Circular Cylinder Numerical Investigation of Flow Field of a Non-Circular Cylinder,' CFD Lett., vol. 11, no. 5, pp. 37-49, 2019.

30. K. A. Pathan, S. A. Khan, and P. S. Dabeer, "CFD Analysis of Effect of Mach number , Area Ratio, and Nozzle Pressure Ratio on Velocity for Suddenly Expanded Flows," in 2nd International Conference for Convergence in Technology (I2CT) CFD, 2017, pp. 1104-1110.

31. K. A. Pathan, S. A. Khan, and P. S. Dabeer, "CFD Analysis of Effect of Area Ratio on Suddenly Expanded Flows," in 2nd International Conference for Convergence in Technology (I2CT) CFD, 2017, pp. 1192-1198.

32. K. A. Pathan, S. A. Khan, and P. S. Dabeer, "CFD Analysis of Effect of Flow and Geometry Parameters on Thrust Force Created by Flow from Nozzle," in 2nd International Conference for Convergence in Technology (I2CT) CFD, 2017, pp. 1121-1125.

33. K. A. Pathan, P. S. Dabeer, and S. A. Khan, "Investigation of base pressure variations in internal and external suddenly expanded flows using CFD analysis," CFD Lett., vol. 11, no. 4, pp. 32-40, 2019.

34. S. A. Khan, M. Asadullah, and J. Sadiq, "Passive Control of Base Drag Employing Dimple in Subsonic Suddenly Expanded Flow," Int J. Mech. Mechatronics Eng., vol. 8, no. 03, pp. 69-74, 2018.

35. S. A. Khan and M. Asadullah, "Passive Control of Base Drag in Compressible Subsonic Flow using Multiple Cavity," Int. J. Mech. Prod. Eng. Res. Dev., vol. 8, no. 4, pp. 39-44, 2018.

36. M. Asadullah, S. A. Khan, W. Asrar, and E. Sulaeman, "Low-Cost Base Drag Reduction Technique,” Int. J. Mech. Eng. Robot. Res., vol. 7, no. 4, pp. 428-432, 2018.

37. M. Asadullah, S. A. Khan, W. Asrar, and E. Sulaeman, "Passive control of base pressure with the static cylinder at supersonic flow," in IOP Publishing House, IOP Conf. Series: Materials Science and Engineering, 2018, pp. 1-10.

38. M. Asadullah, S. A. Khan, W. Asrar, and E. Sulaeman, "Active control of base pressure with the counter-clockwise rotating cylinder at Mach 2," 2017 4th IEEE Int. Conf. Eng. Technol. Appl. Sci., vol. 8 no. 6 , pp. 1-6, 2017. 